\author{
В. А. Глива ${ }^{1}$, О. М. Тихенко ${ }^{1}$, О. В. Ходаковський ${ }^{2}$ \\ ${ }^{1}$ Національний авіаційний університет, Київ, Україна \\ ${ }^{2}$ Національний технічний університет України «КПІ імені Ігоря Сікорського», Київ, Україна
}

\title{
МЕТОДОЛОГІЯ ПРОЕКТУВАННЯ НЕОДНОРІДНИХ ЕЛЕКТРОМАГНІТНИХ ЕКРАНІВ
}

\begin{abstract}
У інженерній практиці у якості технологічних та функціональних отворів у захисних конструкціях використовуються отвори круглої та прямокутної форми, тому предметом дослідження було визначення впливу таких отворів на коефіцієнт екранування. Мета роботи - розробити методологічні засади проектування електромагнітних екранів 3 неоднорідностями різного характеру та надати прийнятний за припущеннями та зручний у практичній діяльності розрахунковий апарат для прогнозування ефективності екранування. Розроблено розрахунковий апарат для прогнозування захисних властивостей електромагнітних екранів та методологію його застосування для проектування екрануючих поверхонь. Запропонований підхід для визначення коефіцієнтів екранування електромагнітних екранів 3 неоднорідностями у вигляді круглих та лінійних отворів, що дозволяє спроектувати екран з необхідними захисними властивостями та 3 потрібною або достатньою кількістю отворів. Запропонована методологія дозволяє проектувати неоднорідні екрани з максимально прийнятною кількістю отворів для забезпечення потрібної вентиляції екранованих високочастотних джерел електромагнітних полів у апаратних аеродромів, лікувальних закладів тощо.
\end{abstract}

Ключ ов і слов а: електромагнітний екран, коефіцієнт екранування, ефективність екранування.

\section{Вступ}

У сучасних умовах різноманітності джерел електромагнітних полів широкого частотного діапазону, які використовуються у виробничих процесах, та значного впливу на електромагнітну обстановку зовнішніх джерел, найбільш ефективними засобами захисту працюючих є застосування електромагнітних екранів. Більшість досліджень щодо технологій їх розроблення $є$ експериментальними і стосуються, в основному, суцільних однорідних поверхонь. Роботи щодо створення неоднорідних екранів (з регулярними отворами різної форми, сітчастих) у частині розрахунків їх ефективності здебільшого базуються на емпіричних або напівемпіричних співвідношеннях, які у багатьох випадках дають значні розбіжності 3 експериментом. Тому актуальною $є$ задача розроблення прийнятного за припущеннями, зручного у користуванні розрахункового апарату для прогнозування захисних властивостей електромагнітних екранів та методології його застосування для проектування екрануючих поверхонь.

Аналіз останніх досліджень і публікацій. Більшість даних, наведених у доступних джерелах щодо неоднорідних електромагнітних екранів, стосуються екрануючих матеріалів з регулярними структурами у тілі (матриці) екрана. Так, у роботах $[1,2]$ наведено результати розрахунків та випробувань ефективності електромагнітних екранів з імплантованими у полімерний матеріал мідних, графітових та залізовмісних лінійних структур (товщиною сотні мікрон і більше). У цих випадках матеріали розглядалися як електромагнітні кристали. Інший підхід до створення електромагнітних екранів реалізовано у дослідженнях [3-5], де у якості екрануючої субстанції використовуються рівномірно розміщені у полімерній матриці металеві та металовмісні нано- та мікрочастинки. Зокрема показано, що коефіцієнти екранування електромагнітних полів як низьких, так і високих частот підвищуються зі збільшенням дис- персності екрануючої субстанції. Але такі матеріали хоча і неоднорідні, але ізотропні за конструкцією. Однією з задач забезпечення потрібних рівнів захисту $\epsilon$, поряд 3 прийнятними коефіцієнтами екранування, необхідність мати отвори у екранах. Такі отвори можуть використовуватися для вводу-виводу кабелів (одиночні), для забезпечення вентиляції, огляду (регулярні). Наявність таких отворів необхідно враховувати при проектуванні екранів. У роботах $[6,7]$ наведено методики розрахунку та результати експериментальних досліджень ефективності електромагнітних екранів за наявності круглих та прямокутних отворів, що узагальнено у дисертаційному дослідженні [8]. Але усі конкретні співвідношення, подані у роботі, емпіричні або напівемпіричні. Не показано, які припущення зроблено при їх визначенні. Тому розрахунки за ними мають великі розбіжності з експериментальними даними, що показано у роботі [9]. В той же час існують добре опрацьовані засади розрахунку впливу неоднорідностей будь-якого походження на ефективність екранування [10-13], які можливо адаптувати для використання фахівцями-практиками у галузі електромагнітної безпеки. Такий підхід реалізовано у роботі [14], де на основі коректних співвідношень отриманий зручний розрахунковий апарат для визначення коефіцієнтів екранування сітчастих електромагнітних екранів у залежності від геометричних характеристик періодичних структур, кутів падіння електромагнітних хвиль тощо.

Постановка завдання. Мета роботи - розробити методологічні засади проектування електромагнітних екранів 3 неоднорідностями різного характеру та надати прийнятний за припущеннями та зручний у практичній діяльності розрахунковий апарат для прогнозування ефективності екранування.

\section{Виклад основного матеріалу}

У інженерній практиці у якості технологічних та функціональних отворів у захисних конструкціях 
використовуються отвори круглої та прямокутної форми. Тому визначимо вплив таких отворів на коефіцієнт екранування. Вважаємо, що товщина стінки металевої пластини з отвором така, що за йо- го відсутності магнітне поле не проникає у закритий простір. Розглянемо достатньо велику провідну пластину з отвором, уздовж якої спрямоване однорідне магнітне поле напруженістю $\mathrm{H}_{0}$.

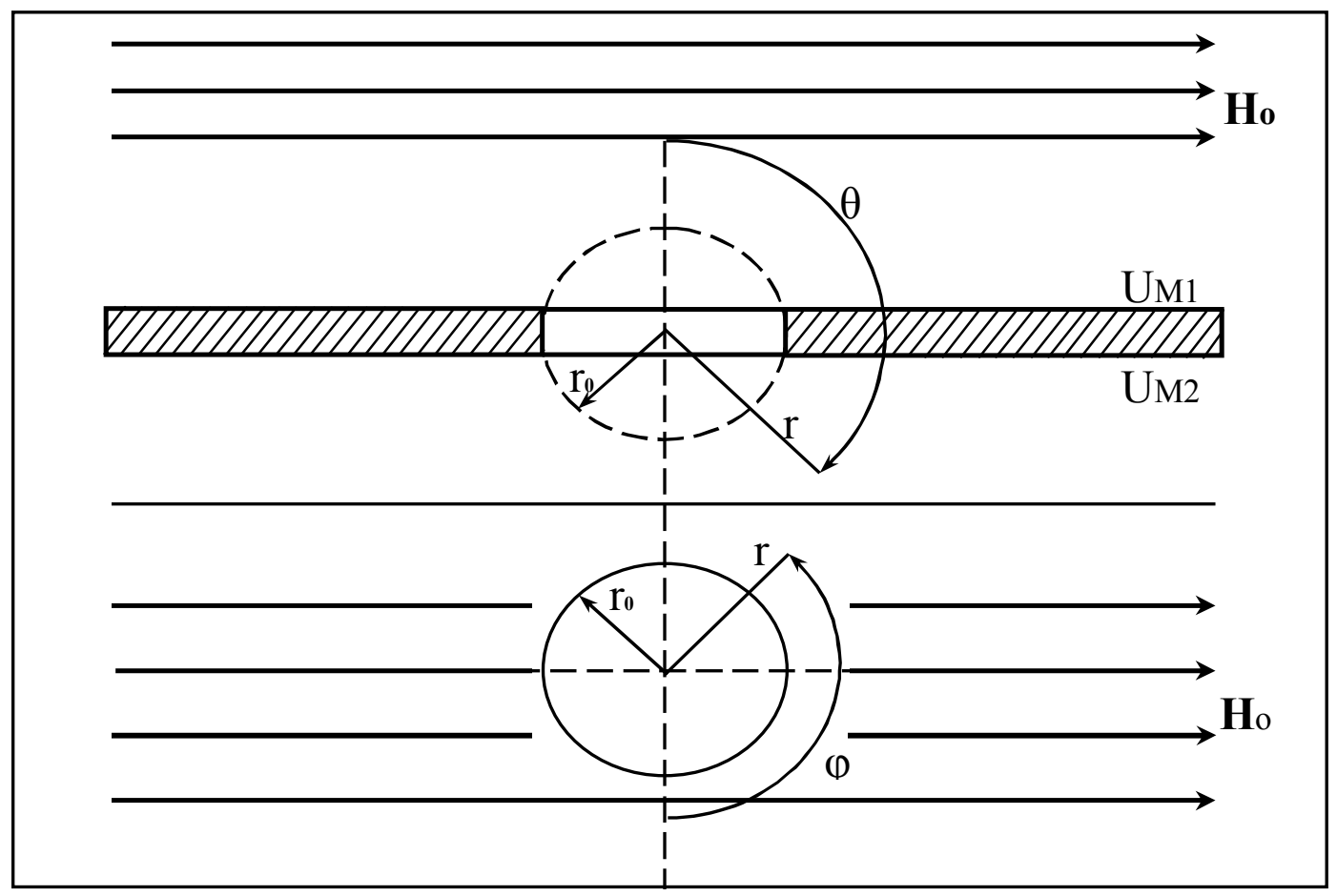

Рис. 1. Екрануюча пластина з круглим отвором

Позначимо скалярний магнітний потенціал поля над пластиною як $U_{M_{1}}$, а $U_{M_{2}}-$ у захищеній зоні. Введемо сферичні координати з початком у центрі отвору $(\mathrm{r}, \theta, \varphi)$. Виходячи $з$ фундаментального співвідношення

$$
\begin{gathered}
H=-\operatorname{grad} U_{M}, \\
\lim _{r \rightarrow \infty} U_{M_{1}}=H_{0} r \sin \theta \sin \varphi, 0<\theta<\frac{\pi}{2} .
\end{gathered}
$$

Рівняння Лапласа має вигляд: $\nabla^{2} U_{M}=0$.

Вважаємо, що частота магнітного поля достатньо висока і воно не проникає у металевий екран:

$$
H_{1}=0, \theta=\pi / 2
$$

Скалярні потенціали у кожній зоні є такими:

$$
\begin{gathered}
U_{M_{1}}=H_{0} r \sin \theta \sin \varphi+\sin \varphi \sum_{n=1,3}^{\infty} C_{n} r^{-n-1} P_{n}(\cos \theta), \\
r \geq r_{0}, \quad 0<\theta<\pi / 2, \\
U_{M_{2}}=-\sin \varphi \sum_{n=1,3}^{\infty} C_{n} r^{-n-1} P_{n}(\cos \theta), \\
r \geq r_{0}, \quad \pi / 2<\theta<\pi .
\end{gathered}
$$

де $P_{n}(\cos \varphi)$ - поліном Лежандра; $\mathrm{C}_{\mathrm{n}}$ - сталі інтегрування (амплітудні значення просторових гармонік поля).

Розв'язання цих рівнянь можна поєднати у одне для зовнішньої області. При умови неперервності дотичних i нормальних складових напруженості магнітного поля на поверхні сферичної зони отвору $\left(\mathrm{r}=\mathrm{r}_{0}\right.$ ) отримуємо системи рівнянь для визначення сталих інтегрування, а 3 них - співвідношення для визначення потенціалів $U_{M_{1}}$ та $U_{M_{2}}$ [10].

Коефіцієнт екранування пласким екраном 3 круглим отвором можна представити у вигляді:

$$
\begin{gathered}
K_{e} \approx U_{M_{1}} / U_{M_{2}}= \\
-\left[\sin \theta+\left(\frac{2}{\pi}\right) \cdot \sum_{n=1,3}^{\infty} \frac{(-1)^{0,5(n-1)}}{n(n+2)}\left(\frac{r_{0}}{r}\right)^{n} P_{n}(\cos \theta)\right] x \\
x\left[\left(\frac{2}{\pi}\right) \cdot \sum_{n=1,3}^{\infty} \frac{(-1)^{0,5(n-1)}}{n(n+2)}\left(\frac{r_{0}}{r}\right)^{n+2} \operatorname{Pn}(\cos \theta)\right]^{-1} .
\end{gathered}
$$

Складність цього виразу уявна через те, що практичну зацікавленість представляє коефіцієнт екранування на великій відстані від отвору $\left(\mathrm{r}>>\mathrm{r}_{0}\right)$, тому можна відкинути усі члени ряду, крім першого. У цьому випадку отримаємо:

$$
K_{e} \approx\left[1-\left(\frac{2}{3 \pi}\right)\left(\frac{r_{0}}{r}\right)^{3}\right]\left[\left(\frac{2}{3 \pi}\right)\left(\frac{r_{0}}{r}\right)^{3}\right]^{-1} .
$$

Як видно, для цього випадку коефіцієнт екранування $\epsilon$ функцією розмірів. Можна також зробити висновок, що отвір діє як магнітний диполь, розташований у центрі отвору, 3 віссю, паралельною спрямованості поля у площині екрана. Момент диполя пропорційний кубу радіусу отвору $\mathrm{r}_{0}$. Цей результат є важливим через те, що надає змогу роз- 
глядати регулярно розташовані отвори (перфорацію) як систему диполів, сумарне поле яких у захищеній зоні можна легко обчислити. У багатьох випадках існують або потрібні щільові отвори або неоднорід- ності (наприклад, місця з’єднання елементів) у електромагнітному екрані.

Розглянемо достатньо довгу (по відношенню до ширини) щілину (рис. 2).

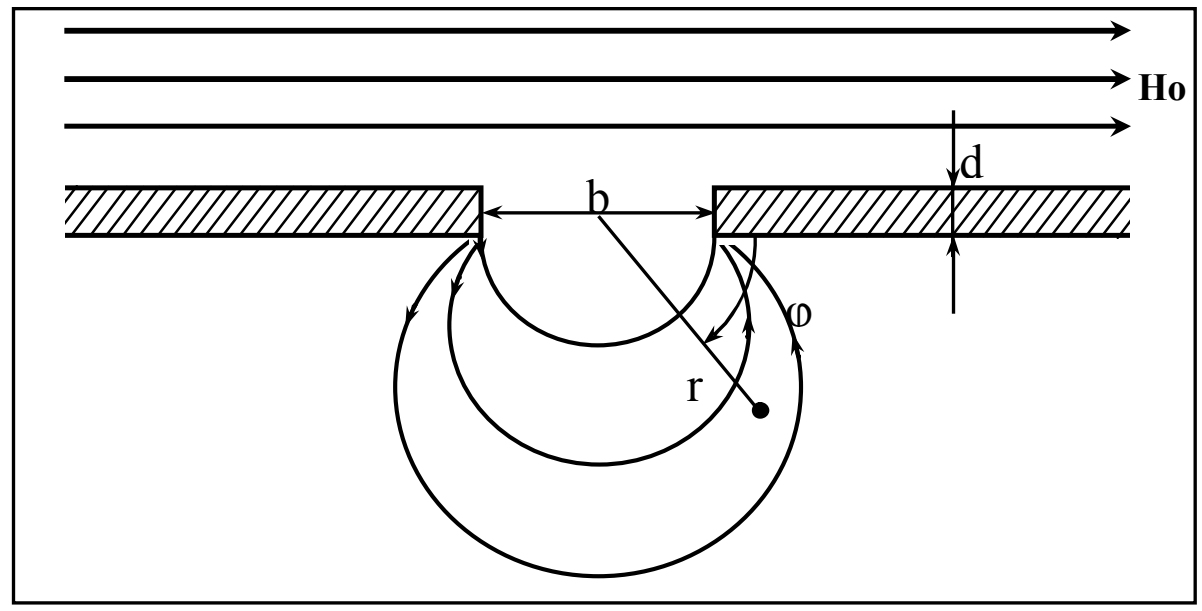

Рис. 2. Екрануюча пластина з круглим отвором

Вважаємо, що стінка екрана має кінцеву товщину, а магнітне поле спрямоване уздовж екрана. У цьому випадку поле усередині екрана можна вважати генерованим магнітним диполем, розташованим усередині щілини. Вісь диполя спрямована паралельно лініям однорідного магнітного поля. Також вважаємо, що змінне магнітне поле проникає крізь поверхню екрана, а щілина достатньо вузька $(\mathrm{b} \leq \mathrm{d})$ [10]. У полярних координатах (r, $\varphi$ ) скалярний магнітний потенціал за екраном визначається як:

$$
\begin{aligned}
U_{M}= & (2 b / \pi)^{2}[1+(1-i) \cdot(2+\pi+\pi d / b) \cdot(\delta / b)] \times \\
& \times \exp [-(\pi d / b+2)] H_{0} \cdot \cos \varphi / r .
\end{aligned}
$$

Фактично глибина проникнення поля у стінку екрана пропорційна еквівалентній глибині проникнення і характеризується кутом фазового зсуву $\pi / 4$. За умови великої частоти глибина зменшується. Напруженість магнітного поля у просторі за екраном з урахуванням $H=-\operatorname{grad}_{M}$ :

$$
\begin{gathered}
H=(2 b /(\pi r))^{2}[1+(1-i) \cdot(2+\pi+\pi d / b) \cdot(\delta / b)] \times \\
\times H_{0} \exp [-(\pi d / b+2)] .
\end{gathered}
$$

Еквівалентна глибина проникнення поля у матеріал екрана визначається зі співвідношення:

$$
\delta=\sqrt{\frac{1}{\pi f \mu_{a} \sigma}},
$$

де $\mathrm{f}$ - частота магнітного поля; $\mu_{a}$ - абсолютна магнітна проникність матеріалу екрана.

Коефіцієнт екранування визначається як

$$
K_{e}=\frac{H_{0}}{H} .
$$

Як видно з наведених співвідношень, коефіцієнт екранування залежить від відстані точки визначення поля до щілини. Крім того, ефективність екранування значною мірою залежить від співвідно- шення $b / d$. Для $\mathrm{b}>>\mathrm{d}$ скалярний магнітний потенціал можна представити у вигляді нескінченних рядів [10]. 3 них випливає, що напруженість магнітного поля у центрі щілини дорівнює $H_{0} / 2$, а коефіцієнт екранування поля, паралельного екрану на великій відстані від отвору ( $>>0,5 \mathrm{~b})$, визначається як:

$$
K_{e}(r) \approx 16 r^{2} / b^{2} .
$$

Якщо поле спрямоване перпендикулярно екрану зі щілиною:

$$
K_{e}(r) \approx[\pi r /(2 b)]^{2} \exp [(\pi d / b)+2] .
$$

Як і у випадку з круглим отвором, той факт, що наявність щілини еквівалентна наявності у цій точці магнітного диполя дозволяє розраховувати коефіцієнт екранування екрана з регулярними прорізами як площини із системою магнітних диполів.

\section{Висновки}

1. Запропонований підхід до визначення коефіцієнтів екранування електромагнітних екранів 3 неоднорідностями у вигляді круглих та лінійних отворів дозволяе спроектувати екран необхідних захисних властивостей $з$ потрібною або достатньою кількістю отворів.

2. Той факт, що наявність отвору у екрані еквівалентна наявності у цьому місці магнітного диполя, який розповсюджує магнітне поле у заекранний простір, надає змогу максимально точно розрахувати ефективність електромагнітних екранів 3 різним типом перфорації.

3. Запропонована методологія дозволяе проектувати неоднорідні екрани на принципі розумної достатності. Максимально прийнятна кількість отворів дозволяє забезпечити потрібну вентиляцію екранованих високочастотних джерел електромагнітних полів у апаратних аеродромів, лікувальних закладів тощо. 
1. Зотов И. С., Бычков И. В., Федий А. А. Исследование амплитудно-частотной характеристики коэффициента пропускания двумерного электромагнитного кристалла, образованного медными цилиндрами. Письма в ЖТФ. Т. 37 . № 23. 2011. C. 39-44.

2. Ceken F., Pamuk G., Ozkurt A., Ugurlu S. Electromagnetic Shielding Properties of Plain Knitted Fabrics Containing Conductive Yarns. Journal of Engineered Fibers and Fabrics. 2012. №. 7. P. 81-87.

3. Bhattacharjee S. Protective Measures to Minimize the Electromagnetic Radiation. Electronic and Electric Engineering. 2014. № 4. P. 375-380.

4. Jalali M., Dauterstedt S., Michaud A., Wuthrich R. Electromagnetic shielding of polymer-matrix composites with metallic nanoparticles. Composites Part B: Engineering. 2011. P. 1420-1426.

5. Glyva V., Lyashok J., Matvieieva I., Frolov V., Levchenko L., Tykhenko O., Panova O., Khodakovskyy O., Khalmuradov B., Nikolaiev K. Development and investigation of protective properties of the electromagnetic and soundproofing screen. Eastern-European Journal of Enterprise Technologies. 2018. № 5 (96). P. 54-61.

6. Демский Д. Ф., Фомина И. А., Марченко М. В. Автоматизация расчетов эффективности экранирования. Технологии ЭМС. 2013. № 1. С. 44-54.

7. Журавлев И. Н., Кечиев Л. Н., Крючков Н. М. Специализированный измеритель напряженности электрического поля для измерения эффективности экранирования. Технологии ЭМС. 2013. № 1. С.23-28.

8. Демский Д. В. Метод расчета эффективности экранирования для неоднородных электромагнитных экранов: диссертация. Москва, 2014. 114 с.

9. Думанський В. Ю., Біткін С. В., Полька Н. С. Стан електромагнітної обстановки в загальноосвітніх закладах, обладнаних комп’ютерною технікою та засобами передачі даних типу WI-FI. Гігієна населених місиь. 2013. №. 62. С. $177-186$.

10. Аполлонский С. М. Справочник по расчёту электромагнитных экранов. Энергоатомиздат. 1998. 224 с.

11. Kuchuk G., Kovalenko A., Komari I.E., Svyrydov A., Kharchenko V.. Improving big data centers energy efficiency: Traffic based model and method. Studies in Systems, Decision and Control, vol 171. Kharchenko, V., Kondratenko, Y., Kacprzyk, J. (Eds.). Springer Nature Switzerland AG, 2019. Pp. 161-183. DOI: http://doi.org/10.1007/978-3-030-00253-4 8

12. Amin Salih M. and Potrus M.Y. (2015), “A Method for Compensation of Tcp Throughput Degrading During Movement Of Mobile Node”, ZANCO Journal of Pure and Applied Sciences, Vol. 27, No 6, pp._59-68.

13. Аполлонский С. М., Логинова И. Д. Построение моделирующих устройств для исследования внешних электрических полей источников. Энергетика и транспорт. 2009. № 1. С. 104-110.

14. Glyva V., Kovalenko V., Levchenko L., Tykhenko O. Research into protective properties of electromagnetic screens based on the metal-containing nanostructures. Eastern-European Journal of Enterprise Technologies. 2017. Is. 3/12 (87). pp. 50-55.

Рецензент: д-р техн. наук, проф. М. І. Адаменко, Харківський національний університет ім. В. Н. Каразіна, Харків Received (Надійшла) 31.05.2019 Accepted for publication (Прийнята до друку) 07.08.2019

\section{Методология проектирования неоднородных электромагнитных экранов}

\section{В. А. Глыва, О. Н. Тихенко, А. В. Ходаковский}

В инженерной практике в качестве технологических и функциональных отверстий в ограждающих конструкциях используются отверстия круглой и прямоугольной формы, поэтому предметом исследования было определение влияния таких отверстий на коэффициент экранирования. Цель работы - разработать методологические основы проектирования электромагнитных экранов с неоднородностями различного характера и предоставить приемлемый по предположениям и удобный в практической деятельности расчетный аппарат для прогнозирования эффективности экранирования. Разработан расчетный аппарат для прогнозирования защитных свойств электромагнитных экранов и методологию его применения для проектирования экранирующих поверхностей. Предложенный подход для определения коэффициентов экранирования электромагнитных экранов с неоднородностями в виде круглых и линейных отверстий, позволяет спроектировать экран с необходимыми защитными свойствами и с нужным или достаточным количеством отверстий. Предложенная методология позволяет проектировать неоднородные экраны с максимально приемлемым количеством отверстий для обеспечения нужной вентиляции экранированных высокочастотных источников электромагнитных полей в аппаратных аэродромов, лечебных учреждениях и тому подобное.

Кл юче вы е сл ов а: электромагнитный экран, коэффициент экранирования, эффективность экранирования.

\section{Methodology of designation of homogeneous electromagnetic screens}

$$
\text { V. Glyva, O. Tykhenko, O. Khodakovskyy }
$$

In engineering practice, holes of circular and rectangular shape are used as technological and functional openings in protective structures, so the object of the study was to determine the effect of such openings on the shielding factor. The purpose of the work was to develop a methodological basis for the design of electromagnetic screens with heterogeneities of different nature and to provide a reasonable and practical calculation device for predicting the efficiency of screening. A calculation apparatus for the prediction of the protective properties of electromagnetic screens and a methodology for its use for the design of shielding surfaces have been developed. An approach is proposed to determine the shielding coefficients of electromagnetic screens with inhomogeneities in the form of circular and linear openings, which allows the design of a screen with the necessary protective properties and with the required or sufficient number of openings. The proposed methodology allows to design inhomogeneous screens with the maximum acceptable number of openings to provide the required ventilation of shielded high-frequency sources of electromagnetic fields in hardware aerodromes, medical institutions, etc.

Keywords : electromagnetic screen, shielding factor, shielding efficiency. 